\title{
Protein-Assisted Room-Temperature Assembly of Rigid, Immobile Holliday Junctions and Hierarchical DNA Nanostructures
}

\author{
Saminathan Ramakrishnan ${ }^{1,2,+}$, Sivaraman Subramaniam ${ }^{3,4,+}$, Charlotte Kielar ${ }^{1, \ddagger}$, \\ Guido Grundmeier ${ }^{1}\left(\mathbb{D}\right.$, A. Francis Stewart ${ }^{3,4}$ (D) and Adrian Keller ${ }^{1, *(D)}$ \\ 1 Technical and Macromolecular Chemistry, Paderborn University, Warburger Str. 100, \\ 33098 Paderborn, Germany; saminathan.ramakrishnan@gmail.com (S.R.); kielar86@hzdr.de (C.K.); \\ guido.grundmeier@uni-paderborn.de (G.G.) \\ 2 Structural Biophysics Laboratory, Center for Cancer Research, National Cancer Institute, \\ Frederick, MD 21702, USA \\ 3 Biotechnology Center, Department of Genomics, Technische Universität Dresden, Tatzberg 47-51, \\ 01307 Dresden, Germany; sivaraman.subramaniam@tu-dresden.de (S.S.); \\ francis.stewart@tu-dresden.de (A.F.S.) \\ 4 Cluster of Excellence Physics of Life, Technische Universität Dresden, 01062 Dresden, Germany \\ * Correspondence: adrian.keller@uni-paderborn.de \\ $\dagger$ These authors contributed equally to this work. \\ $\ddagger$ Present address: Institute of Resource Ecology, Helmholtz-Zentrum Dresden-Rossendorf, \\ Bautzner Landstraße 400, 01328 Dresden, Germany.
}

Academic Editor: Ramon Eritja

Received: 29 September 2020; Accepted: 30 October 2020; Published: 3 November 2020

\begin{abstract}
Immobile Holliday junctions represent not only the most fundamental building block of structural DNA nanotechnology but are also of tremendous importance for the in vitro investigation of genetic recombination and epigenetics. Here, we present a detailed study on the room-temperature assembly of immobile Holliday junctions with the help of the single-strand annealing protein Red $\beta$. Individual DNA single strands are initially coated with protein monomers and subsequently hybridized to form a rigid blunt-ended four-arm junction. We investigate the efficiency of this approach for different DNA/protein ratios, as well as for different DNA sequence lengths. Furthermore, we also evaluate the potential of Red $\beta$ to anneal sticky-end modified Holliday junctions into hierarchical assemblies. We demonstrate the Red $\beta$-mediated annealing of Holliday junction dimers, multimers, and extended networks several microns in size. While these hybrid DNA-protein nanostructures may find applications in the crystallization of DNA-protein complexes, our work shows the great potential of $\operatorname{Red} \beta$ to aid in the synthesis of functional DNA nanostructures under mild reaction conditions.
\end{abstract}

Keywords: DNA nanotechnology; Holliday junctions; atomic force microscopy; single-strand annealing proteins; $\operatorname{Red} \beta$

\section{Introduction}

The Holliday junction $(\mathrm{HJ})$ is an intermediate DNA structure involved in genetic recombination and DNA repair. The biological significance of HJs includes facilitating the strong binding of regulatory proteins and target sites of recognition signals during replication [1]. The folding or emergence of double helical junctions and their stability strongly rely on three critical factors: base stacking [2], sequence composition [3], and ionic strength [4]. However, innate branch migration in HJs is a distinct phenomenon that makes the $\mathrm{HJ}$ structures highly unstable [5]. Active pair exchange between bases in homologous strands and in particular at the branch points migrates the 
sequences along the structure until the HJ eventually disappears [6]. For previous structural and functional analyses, the in vitro production of HJs was required. Thereby, it became possible to understand how junction-resolving enzymes such as resolvases bind and split the duplexes in the $\mathrm{HJ}$ structures, which is an essential event in recombination [7]. Furthermore, the synthesis of immobile HJs is a cornerstone of structural DNA nanotechnology [8]. Initially, Seeman designed immobile $\mathrm{HJ}$ structures by reevaluating the concept of branch point migration and its influence on junction instability with the aim to arrange them in three-dimensional crystal lattices. [9]. Seeman et al. also studied the orientation-specific cleavage function of resolvase enzymes in synthetic HJ structures [10] and other critical biophysical characteristics [11-15]. The immediate applications of such synthetic HJs also included the understanding of functional proteins [16] and epigenetic markers [17], as well as applications in biomolecular engineering [18]. Importantly, in DNA nanotechnology, the concept of immobile $\mathrm{HJ}$ synthesis linked to a peculiar sticky-end strategy was employed to assemble highly ordered crystal-like lattices in two and three dimensions. Unfortunately, this strategy usually requires complex and time-consuming thermal annealing protocols, which in extreme cases may extend over several days [19], while typically resulting in only moderate synthesis yields. Consequently, there is a need for fast and low-temperature strategies for DNA nanostructure synthesis with high assembly yields [20-26].

Many phages encode their own homologous recombination systems often as $5^{\prime}-3^{\prime}$ exonucleases paired with single-strand annealing proteins (SSAPs). In the lambda phage, the red recombination system includes lambda exonuclease $(\operatorname{Red} \alpha)$ paired with the SSAP $\operatorname{Red} \beta$ [27]. Genome integrity is maintained by repair of double-strand breaks (DSB) through homology directed repair (HDR) [28]. One of the reaction pathways of HDR involves single-strand annealing (SSA) mediated by SSAPs. SSAPs have been divided into two categories, namely ATP-dependent, e.g., RecA and Rad51, and ATP-independent, which in particular includes $\operatorname{Red} \beta$ [29]. $\operatorname{Red} \beta$ is a $30 \mathrm{kDa}$ protein and a central player in the recombinant DNA engineering method called recombineering [30-32]. In the absence of DNA, Red $\beta$ polymerizes to form a shallow right-handed helix. Upon annealing two DNA strands, Red $\beta$ forms a very stable left-handed helical nucleoprotein filament (Figure 1a). These filaments have a curved form without rigid edges [29]. Optical tweezer single-molecule studies revealed that the $\operatorname{Red} \beta$ nucleoprotein filament is nucleated by a remarkably stable DNA clamp to initiate HDR [33], while biochemical studies have established a complete model of HDR [34]. In this work, we utilized the annealing efficiency of Red $\beta$ to coat single-stranded (ss) DNA with Red $\beta$ monomers and then anneal them to complementary sequences to form DNA nanostructures based on rigid HJ motifs. The aim of this work was to (i) assess the potential of $\operatorname{Red} \beta$ in the in vitro assembly of complex DNA structures, (ii) investigate whether the protein-coated DNA nanostructures provide a viable route for crystallizing the DNA-protein complexes, and (iii) produce extended lattices of rigid DNA-protein nanostructures at room temperature for applications in nanoelectronics [35,36], plasmonics [37,38], and molecular lithography $[39,40]$.

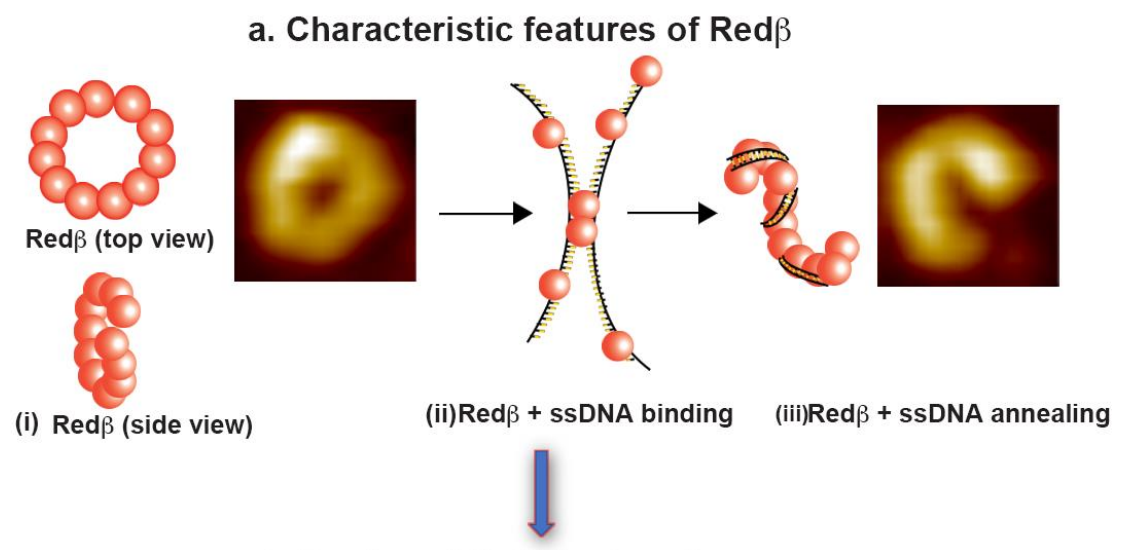

Figure 1. Cont. 


\section{b. Design of Holliday junction}

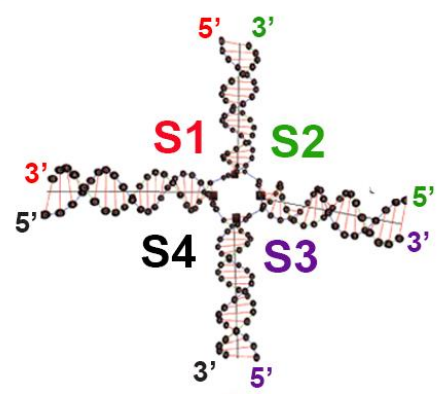

c. Optimization of ratios of DNA to $\operatorname{Red} \beta$

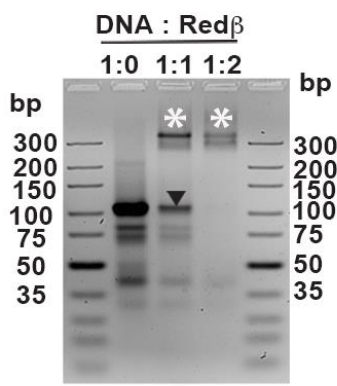

\section{d. $\operatorname{Red} \beta$-mediated Holliday junction assembly}

(i) Holliday junction assembly

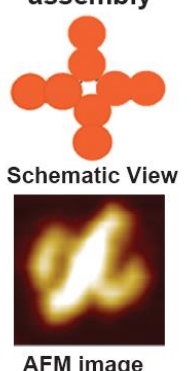

(ii) Hierarchical structure assembly

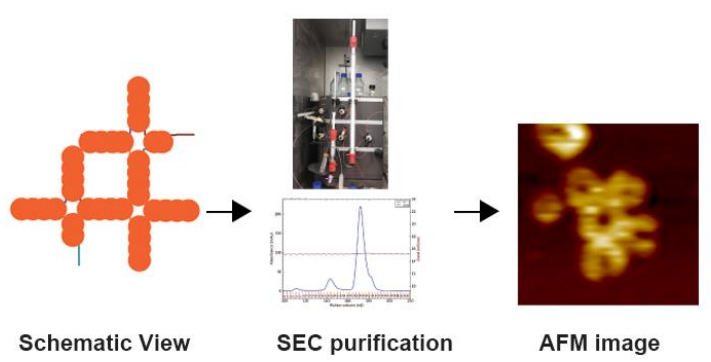

Figure 1. Experimental strategy for the Red $\beta$-mediated assembly of Holliday junction (HJ) structures. (a) Characteristic features of $\operatorname{Red} \beta$. Models of the $\operatorname{Red} \beta$ quaternary structure are shown for the protein alone $\left(20 \times 20 \mathrm{~nm}^{2}\right)$, in complex with ssDNA, and in an annealed complex in the presence of two complementary ssDNA $\left(20 \times 20 \mathrm{~nm}^{2}\right)$. The models were adapted from [29]. (b) Design of HJ structures. Different HJ structures composed of four ssDNA strands (S1-S4) were designed using UNIQUEMER 3D [41] and employed as substrates in this study. (c) Optimization of DNA/Red $\beta$ ratios by gel electrophoresis. The arrowhead pointing downwards indicates the free ssDNA, while the asterisks indicate the assembled HJ structures. (d) HJ assembly by Red $\beta$. (i) Schematic view and atomic force microscopy (AFM) image of a single HJ structure $\left(50 \times 50 \mathrm{~nm}^{2}\right)$. (ii) Schematic view, size exclusion chromatography (SEC) purification, and AFM image of a hierarchical HJ assembly $\left(100 \times 100 \mathrm{~nm}^{2}\right)$.

Few previous attempts to employ proteins in the construction of DNA nanostructures have been reported. For instance, Praetorius et al. made efforts to synthesize a complete DNA origami nanostructure through stitching complementary sequences by DNA-binding TAL proteins [42]. The TAL proteins not only annealed but also provided rigidity to the DNA origami structures. Similarly, Schiffels et al., demonstrated the stiffening of flexible dsDNA structures using the HDR protein RecA [43]. In contrast to these proteins, however, $\operatorname{Red} \beta$ does not form linear protein-DNA filaments but rather 
ring-like structures in the presence and absence of complementary ssDNA (see Figure 1a). While this intrinsic curvature may impose some limitations to nanostructure assembly, it may also present a possibility to synthesize more complex shapes and structures. Upon ssDNA binding, Red $\beta$ breaks into different nucleoprotein filaments depending on the length of the ssDNA (see Figure 1a) [29]. When a complementary ssDNA sequence is added, a highly stable dsDNA-protein complex is formed. Since it does not require ATP to anneal, this Red $\beta$-assisted duplex formation occurs already at room temperature. During annealing, every Red $\beta$ protein monomer occupies approximately 11 bases in the ssDNA sequence, and efficient DNA annealing requires at least $15-20$ base pairs [29]. Therefore, we have designed different four-arm HJ structures from 44 mer, 66 mer, and 88 mer oligonucleotides (Figure 1b). After determining the optimal ssDNA/Red $\beta$ ratio for $\operatorname{Red} \beta$-assisted annealing (Figure 1c), the HJ structures were assembled at room temperature and characterized by atomic force microscopy (AFM, Figure 1d). Furthermore, we also have synthesized hierarchical assemblies of HJ structures (Figure 1d) in order to assess the ability of Red $\beta$ to form complex and extended DNA nanostructures and pave the way for its inclusion in the DNA nanotechnology toolkit.

\section{Results and Discussion}

\subsection{Assembly of Blunt-End HJ Structures from 44 mer, 66 mer, and 88 mer Oligonucleotides at $37^{\circ} \mathrm{C}$}

In a 44 mer HJ structure, every arm has a 22 mer dsDNA sequence. In order to estimate the optimal ssDNA/Red $\beta$ ratio during Red $\beta$-assisted assembly, different ratios ranging from 1:1 to 1:4 were tested. For this, the individual strands S1-S4 were first coated with $\operatorname{Red} \beta$ at $37^{\circ} \mathrm{C}$, subsequently mixed together, and incubated at $37^{\circ} \mathrm{C}$ in order to anneal the $\mathrm{HJ}$ structure. Interestingly, even for the DNA mixture without $\operatorname{Red} \beta$, a significant shift of the corresponding band is observed in the gel image in Figure 2. This indicates that at this temperature, there is already some hybridization of the four partially complementary ssDNAs occurring. In the presence of $\operatorname{Red} \beta$, however, a much stronger shift is observed. In particular, at an ssDNA/Red $\beta$ ratio of $1: 1$, the agarose gel analysis shown in Figure 2 reveals a broad band corresponding to the ssDNA completely coated with Red $\beta$ monomers with some fast-migrating bands corresponding to residual ssDNA sequences with incomplete Red $\beta$ coating. Increasing the Red $\beta$ concentration resulted in all ssDNA sequences being coated with no residual ssDNA detected. The gel bands have a smeared look due to the weak interaction of ssDNA with $\operatorname{Red} \beta$. From these initial tests, we have decided to use 1:1 and 1:2 ratios of ssDNA/Red $\beta$ to achieve complete coating of the oligonucleotides and promote $\mathrm{HJ}$ assembly. After incubating the individual ssDNA strands with $\operatorname{Red} \beta$, all four sequences were mixed to form the HJ structure at room temperature. However, the AFM image of the assembled HJ structures in Figure 2 shows plenty of full rings and few C-shaped structures corresponding to free $\operatorname{Red} \beta$ and incomplete $\mathrm{HJ}$ structures even at an ssDNA/Red $\beta$ ratio of 1:2. This mixture of structures further supports the weak binding of Red $\beta$ to short ssDNA sequences. Nevertheless, a few four-arm HJ structures can be identified in the AFM image in Figure 2 and are in fair agreement with the design (see the schematic structure in Figure 2). Since each arm can accommodate about two monomers, each of them exhibits a tiny protrusion. Typically, the ring-like structure formed by the Red $\beta$ monomers has a height of approximately $3 \mathrm{~nm}$ [29], which is in good agreement with height of the HJ arms as observed in the height profile in Figure 2. Furthermore, patches of increased height are visible in the center of the four-arm $\mathrm{HJ}$ structure due to the crossover of the protein-DNA filaments.

The 66 mer ssDNA sequence was tested with $\operatorname{ssDNA} / \operatorname{Red} \beta$ ratios of 1:1 and 1:2. The broader bands of the Red $\beta$-ssDNA complex observed in Figure 3 may indicate a slightly increased affinity of $\operatorname{Red} \beta$ to the longer ssDNA sequence. Unlike the case of the 44 mer oligonucleotide, the gel analysis in Figure 3 shows that the 66 mer sequence has been completely coated with Red $\beta$ already at an ssDNA/protein ratio of 1:1. The AFM image in Figure 3 shows the 66 mer HJ structures assembled at this ratio. No full ring structures corresponding to Red $\beta$ monomers assembled without DNA are observed in this sample, which is thus indicative of the complete saturation of the ssDNA sequences. 
The 66 mer HJ structures are composed of two half-ring shapes connected at the central crossover point. Since each $33 \mathrm{bp}$ arm can accommodate about three Red $\beta$ monomers, a total of six monomers are present on one half of the HJ structure. It is known from the literature [29] that a complete Red $\beta$ ring is composed of 11-12 monomers. In agreement with that, the AFM image in Figure 3 shows that the six monomers on each side of the crossover point of the HJ form a half-ring, resulting from the natural curvature of the Red $\beta$ filament, which bends the dsDNA arms of the HJ structures upon addition of a third monomer.
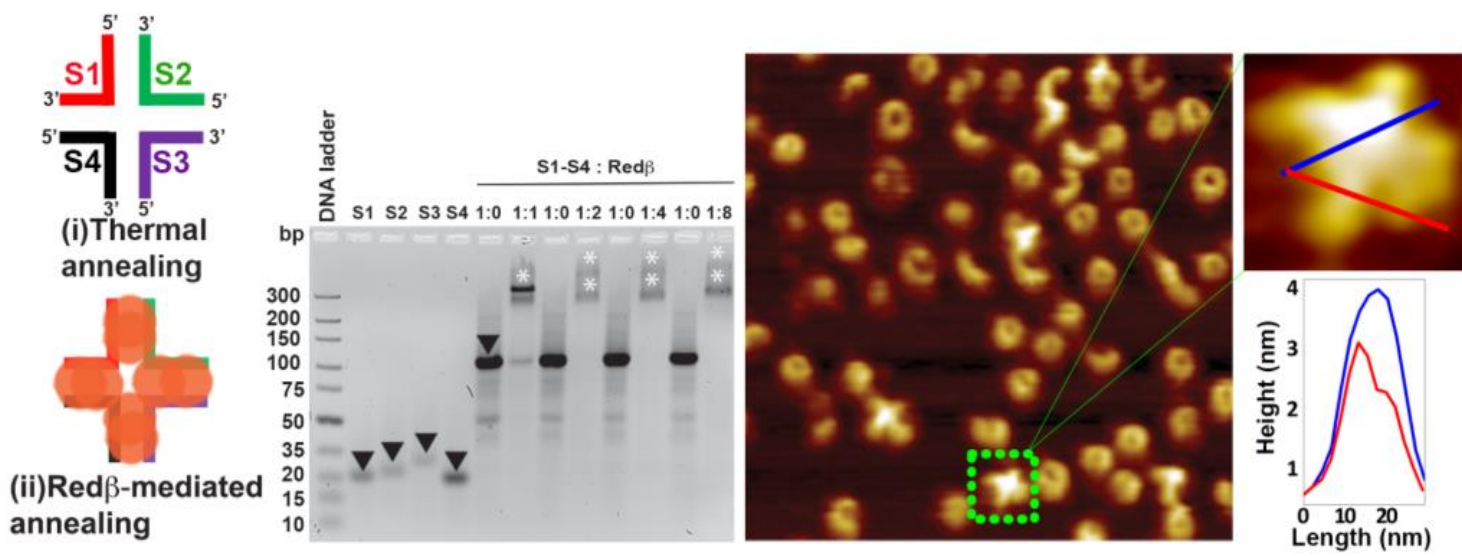

Figure 2. The schematic structures show the 44 mer HJ junction design assembled by thermal (i) and $\operatorname{Red} \beta$-mediated (ii) annealing. The sodium borate agarose gel analysis shows the saturation concentration ratio of Red $\beta$ to ssDNA. The downward-facing arrowheads (black) in lanes S1, S2, S3, and $\mathrm{S} 4$ of the gel image indicate the free ssDNA, while the asterisks indicate the HJ structures. The black downward-facing arrowhead in the first lane 1:0 indicates self-annealed HJ structures without protein. Note that the apparent differences in $\mathrm{HJ}$ band intensity for the different ssDNA/Red $\beta$ ratios are not due to any loss of DNA but rather due to a smearing of the bands (indicated by further asterisks), which results from the formation of a variety of different DNA-protein complexes. The AFM image depicts the resulting Red $\beta$-mediated $\mathrm{HJ}$ assemblies. The height profiles were taken along the lines indicated in the zoom. The AFM image has a size of $300 \times 300 \mathrm{~nm}^{2}$ and a height scale of $4 \mathrm{~nm}$.

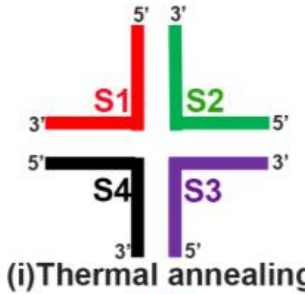

(i)Thermal annealing

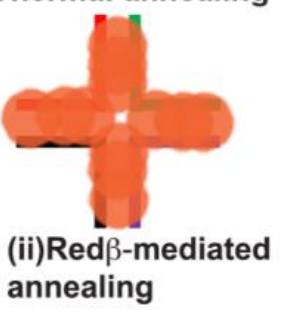

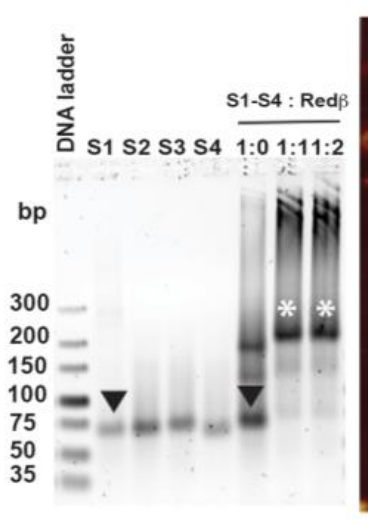
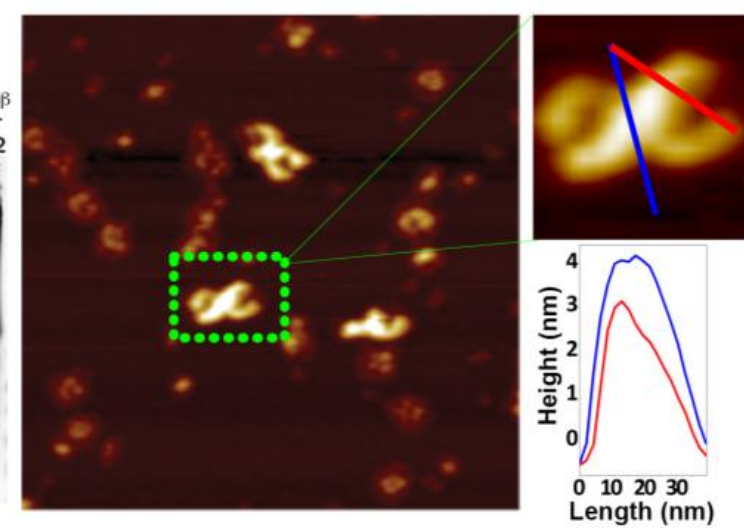

Figure 3. The schematic structures show the 66 mer HJ junction design assembled by thermal (i) and $\operatorname{Red} \beta$-mediated (ii) annealing. The sodium borate agarose gel analysis shows the saturation concentration ratio of $\operatorname{Red} \beta$ to ssDNA. The downward-facing arrowheads (black) in the gel image indicate the free ssDNA, while the white asterisks indicate the HJ structures. The AFM image depicts the resulting Red $\beta$-mediated $\mathrm{HJ}$ assemblies. The height profiles were taken along the lines indicated in the zoom. The AFM image has a size of $300 \times 300 \mathrm{~nm}^{2}$ and a height scale of $4 \mathrm{~nm}$. 
The 88 mer oligonucleotides were also incubated with ssDNA/Red $\beta$ ratios of 1:1 and 1:2. As can be seen in the gel analysis in Figure 4, the ssDNA sequences are not completely coated at the 1:1 ratio, which can be attributed to the larger number of available Red $\beta$-binding sites in the longer ssDNA strands. At this ratio, a large fraction of free ssDNA is observed in the form of fast-migrating bands. At an ssDNA/Red $\beta$ ratio of $1: 2$, however, complete saturation of ssDNA with $\operatorname{Red} \beta \operatorname{monomers}$ is observed with the corresponding band migrating much slower. Moreover, the completely saturated band at the 1:2 ratio looks very faint compared to the case of the 66 mer oligonucleotide (see Figures 3 and 4). These observations indicate that the interaction affinity of $\operatorname{Red} \beta$ and ssDNA weakens once the ssDNA sequence exceeds a certain length. In the AFM image of the assembled 88 mer HJ structures in Figure 4 , there are many full rings and plenty of half-rings observed at an ssDNA/Red $\beta$ ratio of 1:1. Due to their long sequence length, it may be possible for the 88 mer HJ structures to show partially and completely closed rings on both sides of the crossover point. There are about four monomers bound on each $44 \mathrm{bp}$ arm, corresponding to $1 / 3$ of the complete ring shape. When the four monomers in each of the four arms come together, their intrinsic curvature yields a HJ structure composed of two almost ring-like shapes with a prominent bulge at the crossover point.

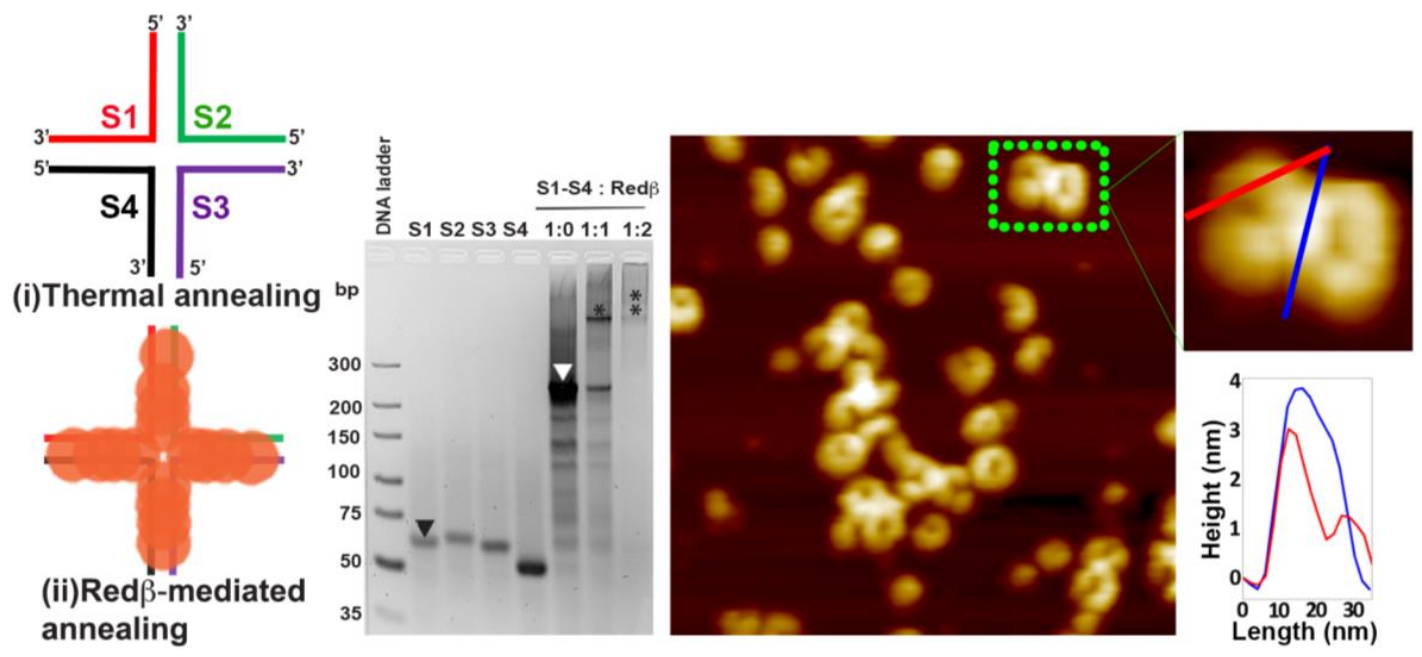

Figure 4. The schematic structures show the 88 mer HJ junction design assembled by thermal (i) and $\operatorname{Red} \beta$-mediated (ii) annealing. The sodium borate agarose gel analysis shows the saturation concentration ratio of $\operatorname{Red} \beta$ to ssDNA. The downward-facing black and white arrowheads in the gel image indicate the free ssDNA and self-annealed HJ structures without protein, respectively, while the asterisks indicate the protein-annealed HJ structures. The AFM image depicts the resulting Red $\beta$-mediated HJ assemblies. The height profiles were taken along the lines indicated in the zoom. The AFM image has a size of $300 \times 300 \mathrm{~nm}^{2}$ and a height scale of $4 \mathrm{~nm}$.

Lilley described two broad classes of HJ conformations, namely open and stacked [44]. The open conformation has a characteristic feature of four arms being at a $90^{\circ}$ angle to each other with a lack of central base pairing. The stacked form has a characteristic feature of slow branch migration as shown by several studies $[5,6,45]$ and is characteristic for the $H J$ in the absence of proteins. Red $\beta$, however, adopts a characteristic right-handed helix in the absence of DNA and changes its helicity to being left-handed upon ssDNA annealing (see Figure 1) [29], with the characteristic C shapes of the DNA-protein filaments indicating strong DNA bending. Based on our current understanding, this Red $\beta$-induced bending of the DNA strands will probably affect the conformation of the assembled HJ, which may thus deviate from the known isomers described above. However, further crystallographic or numerical studies will be required to elucidate the detailed DNA conformations of the different Red $\beta$-mediated HJ structures. 


\subsection{Hierarchical Assembly of HJ Structures with Sticky Ends}

We have further designed HJ structures with sticky ends for hierarchical assembly. The experimental strategy for hierarchical self-assembly is outlined in Figure 5. For the purification of the single HJ structures and hierarchical assembly, the amount of $\operatorname{Red} \beta$ has to be scaled up in order to meet the detection limit of the SEC purification methodology. For this, we have chosen an ssDNA/Red $\beta$ ratio of 1:25 based on our experimental results when 88 mer were purified by SEC (see Supplementary Materials).
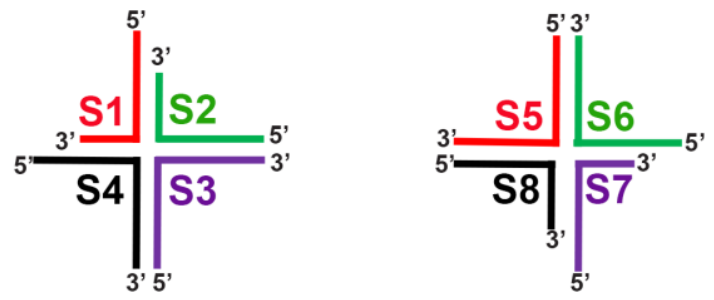

Holliday junction forming ssDNA strands were individually mixed with Red $\beta$

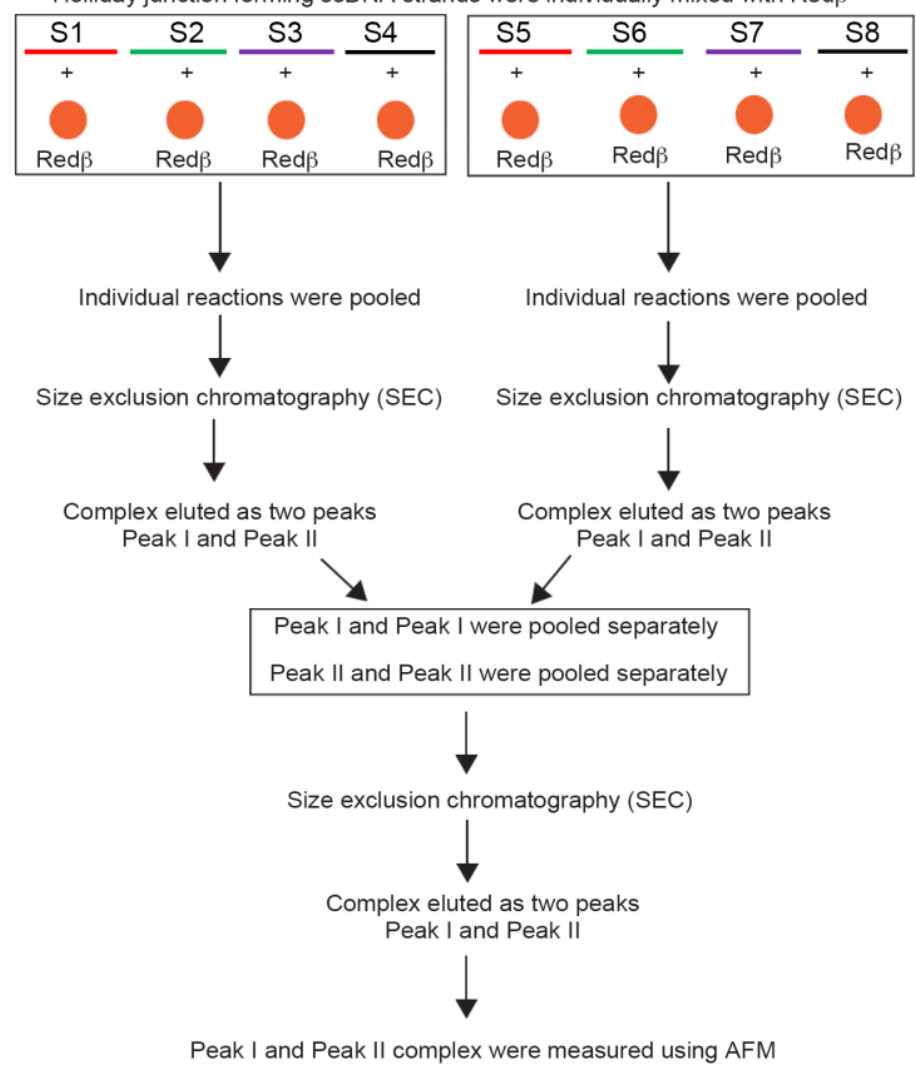

Figure 5. Experimental strategy for species enrichment of S1S4 and S5S8 HJ structures and purification of final hierarchical assemblies using SEC.

The schematic structure in Figure 6a shows that two arms (S2S3 and S3S4) of the S1S4 HJ structure are ds 44 mer, which can accommodate about four Red $\beta$ monomers. The other two arms (S4S1 and S1S2) are each composed of two domains: a ds 22 mer close to the crossover point and an ss 22 mer at the distal end of the arm, which is acting as a sticky end. A similar design is also employed for the S5S8 HJ structure (Figure 6b). In the S1S4 HJ structure, the sticky ends of the S4S1 and S1S2 arms are complementary to those of the S6S7 and S7S8 arms of the S5S8 HJ structure, respectively. Interestingly, we observed efficient HJ structure assembly by $\operatorname{Red} \beta$ at $(23 \pm 2){ }^{\circ} \mathrm{C}$. Therefore, from here on, we performed $\mathrm{HJ}$ assembly as well as hierarchical assembly using $\operatorname{Red} \beta$ at $23^{\circ} \mathrm{C}$. The individual Red $\beta$-assembled S1S4 and S5S8 HJ structures were subjected to SEC for enrichment of the individual species (see Figure 5 and Materials and Methods). The enriched species from the two peaks obtained in 
SEC and fractions from each peak's summit were pooled and analyzed along with load and concentrated samples by agarose gel electrophoresis (see Figure 6). For the S1S4 and S5S8 designs, the SEC loads show the presence of HJ species (see asterisks in the corresponding lanes in Figure 6). Pooled and concentrated Peak I fractions show the presence of free DNA substrates (black arrowheads), while the Peak II samples show complete saturation (asterisks). The AFM image of the S1S4 HJ structures in Figure 6a shows highly concentrated single species with sticky ends at two of the arms. Since the S2S3 and S3S4 arms have lengths of 44 nucleotides, many S1S4 HJ structures have an almost closed ring at one side and a half-ring at the other. Nevertheless, a certain variability of $\mathrm{HJ}$ structures is observed and can be attributed to the presence of different numbers of Red $\beta$ monomers. Upon binding with ssDNA, the Red $\beta$ monomers adhere and grow filaments of multiple lengths. Therefore, an 88 mer ssDNA does not necessarily have to be occupied by precisely eight $\operatorname{Red} \beta$ monomers. If there are only seven monomers on an 88 mer ssDNA instead of eight, the HJ structure will exhibit a slightly different length and curvature. For instance, there are HJ structures observed with one arm being shorter than the others or even missing completely (highlighted by green arrows in Figure 6), which demonstrates the necessity of enriching the individual species. Even though the individual species of S1S4 and S5S8 were enriched by SEC, there are still plenty of incomplete HJ structures observed in the AFM images in Figure 6 that have only one, two, or three arms.

(a)
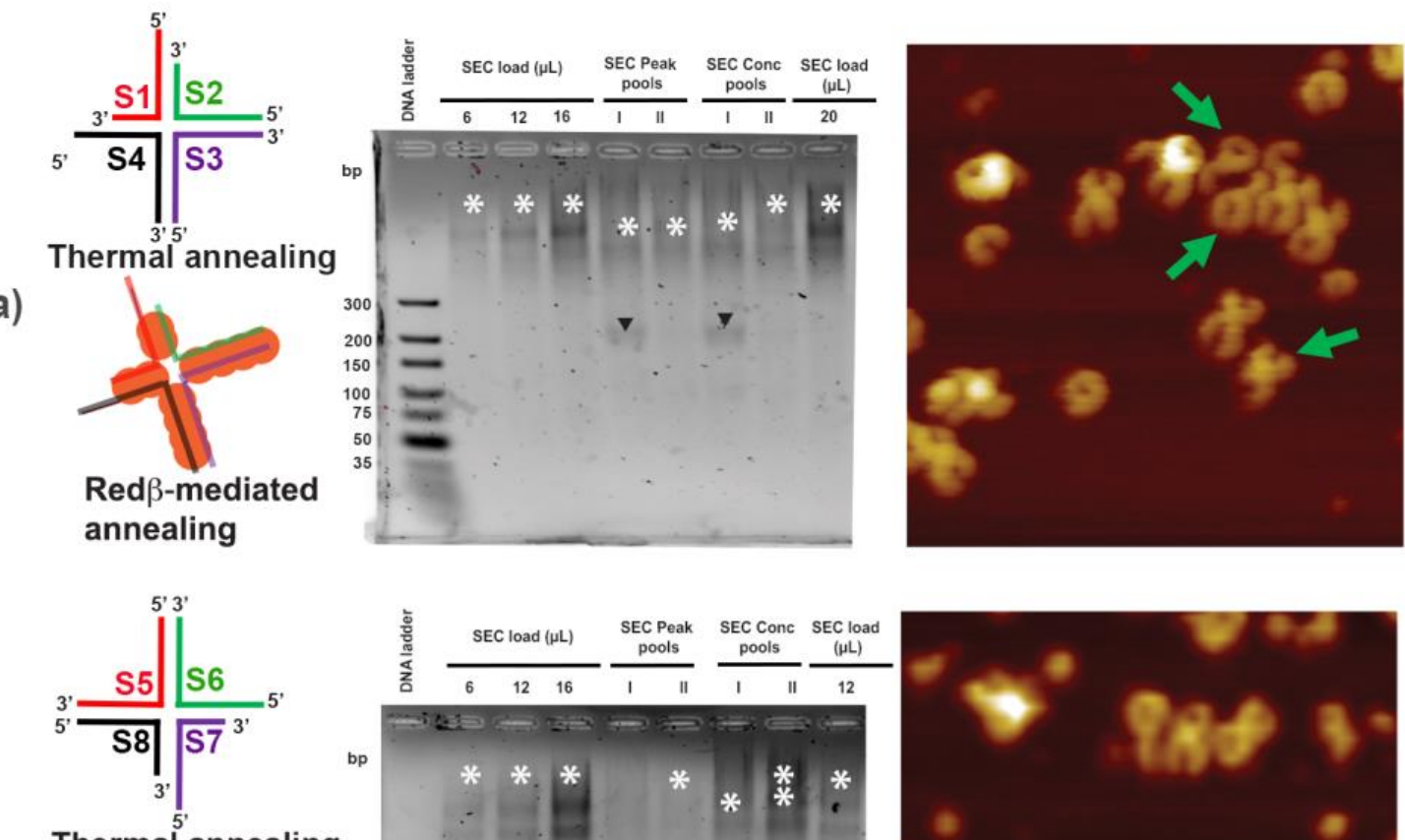

(b)
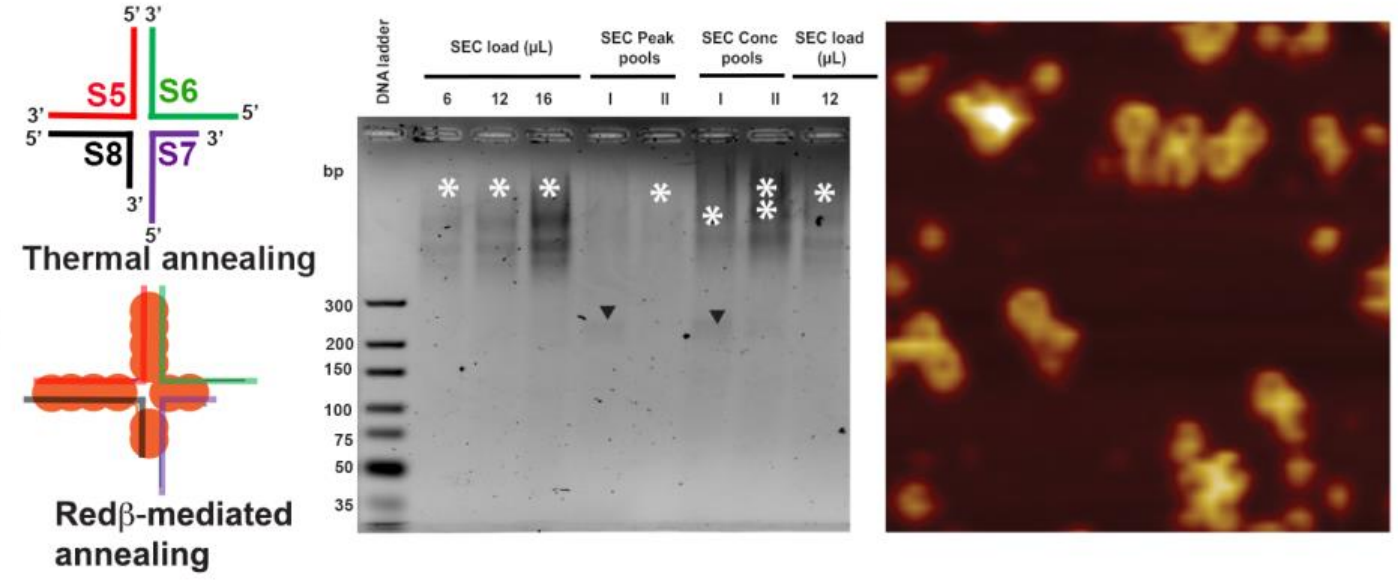

Figure 6. The schematic structures show the (a) S1S4 and (b) S5S8 HJ junction designs assembled by thermal and Red $\beta$-mediated annealing. The corresponding sodium borate agarose gel analyses were conducted with the input and the pooled fractions after SEC, as explained in Figure 5. The downward-facing arrowheads in the gel image indicate the free ssDNA, while the asterisks indicate the HJ structures. The AFM images of Peak I (see Figure 5) were recorded after SEC purification. The AFM images show completely formed HJ structures with the green arrows indicating HJ structures with one arm missing. The AFM images have a size of $300 \times 300 \mathrm{~nm}^{2}$ and a height scale of $4 \mathrm{~nm}$. 
For hierarchical assembly, Peak I and Peak II from the S1S4 assembly were mixed with the corresponding Peak I and Peak II from the S5S8 assembly, respectively. Four discrete bands can be seen in the lane corresponding to the concentrated Peak I of S1S4 and S5S8 HJ structures after SEC (gel image in Figure 7, white asterisks). Surprisingly, the Peak II combination did not show any hierarchical assemblies (see Figure 7). Therefore, the Peak I sample was used for AFM imaging. Several different structures were observed by AFM (see Figure S2), a selection of which is shown in Figure 7. Both the S1S4 and S5S8 HJ structures have shapes consisting of a closed ring connected to a half-ring due to the differences in the dsDNA domains in the different arms. When one S1S4 and one S5S8 anneal with each other, however, they form structure (ii), which resembles a chain of three closed rings (see Figure 7). There are plenty of such chain-like structures observed in the AFM images in Figure S2. In some structures, however, individual arms are missing, or additional arms are present (see Figure 7, structures (iii) and (iv)). Interestingly, if one of the sticky arms of the S1S4-S5S8 dimer is free and anneals with a complementary ssDNA-Red $\beta$ complex, it will form a 2D square lattice structure (i) as seen in the corresponding AFM image in Figure 7. Formation of multiple-ring structures is also possible due to a cross-linking of free sticky arms with hierarchical structures. In summary, any free S1S4 and S5S8 structure can anneal with any complementary sticky end, as observed after SEC purification in the AFM images in Figure 7. Therefore, we next attempted to assemble individual 66 mer HJ structures into extended hierarchical networks.

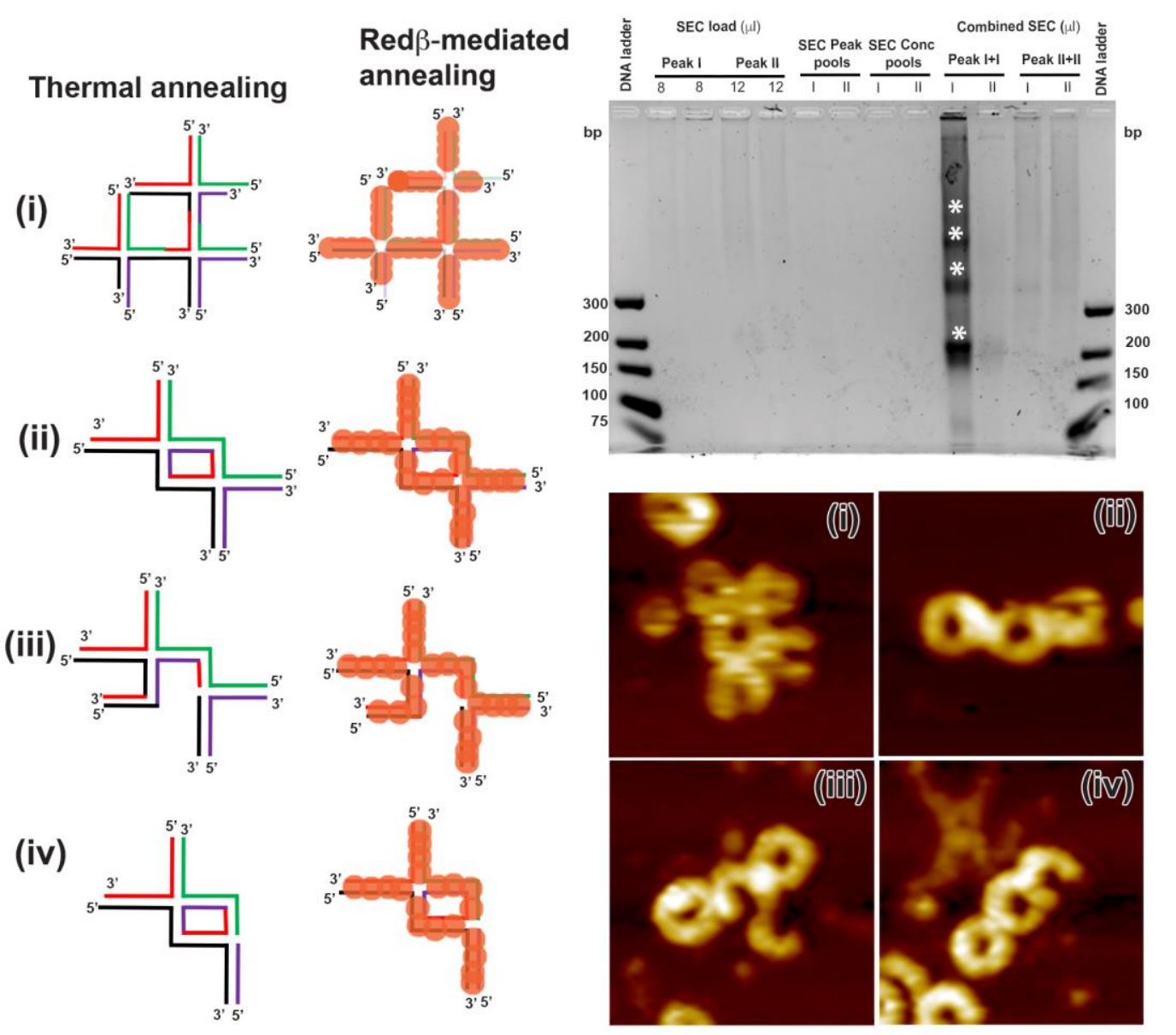

Figure 7. The schematic structures show possible hierarchical assemblies composed of S1S4 and S5S8 $\mathrm{HJ}$ junction structures assembled by thermal and $\operatorname{Red} \beta$-mediated annealing. The corresponding sodium borate agarose gel analysis was conducted with the input and the pooled fractions after SEC, as explained in Figure 5. The asterisks indicate the hierarchical HJ assemblies. The AFM images of Peak I (see Figure 5) were recorded after SEC purification and show hierarchical $\mathrm{HJ}$ assemblies corresponding to the schematic structures (i-iv). The AFM images have a size of $125 \times 125 \mathrm{~nm}^{2}$ and a height scale of $4 \mathrm{~nm}$. 


\subsection{Assembly of Hierarchical Networks Composed of 66 mer HJ Structures}

We aimed at a two-dimensional hierarchical structure assembly by designing a 66 mer HJ structure with self-complementary arms in its structure. In this HJ structure, each arm is composed of a 22 mer ds domain and a 22 mer sticky end. The sticky end of arm S12S9 is complementary to that of arm S10S11, whereas the sticky end of arm S9S10 is complementary to that of arm S11S12 (see the schematic structures in Figure 8). Individual sequences were first treated with $\operatorname{Red} \beta$ for annealing and subjected to SEC (see Materials and Methods) followed by agarose gel electrophoresis to analyze the two peak fractions. However, we found that the concentrated Peak I and Peak II fractions contained structures that were too large to enter the gel even after a long run (see gel analysis in Figure 8, arrowhead). The rapid Red $\beta$-mediated assembly of large complex structures is also evident from the AFM image in Figure 8. The four sticky arms of the HJ structures were annealed with self-complementary arms in all the directions, thus forming a huge clump. When analyzed carefully, the clump has numerous highly branched microstructures (see AFM zoom in Figure 8). Since the dsDNA-Red $\beta$ complex can exhibit highly flexible structural conformations in all directions, the polymerization reaction extended in all directions until the free sticky ends were depleted. The sizes of the clumps observed in the AFM images were thus of the order of several microns. Such mesh-like structures may be interesting for the crystallographic investigation of Red $\beta$-dsDNA complexes and thereby provide a better biophysical understanding of recombineering. Moreover, this extraordinary ability of $\operatorname{Red} \beta$ to anneal complex dsDNA assemblies at room temperature may open up possible applications of $\operatorname{Red} \beta$ and other SSAPs in DNA nanotechnology.
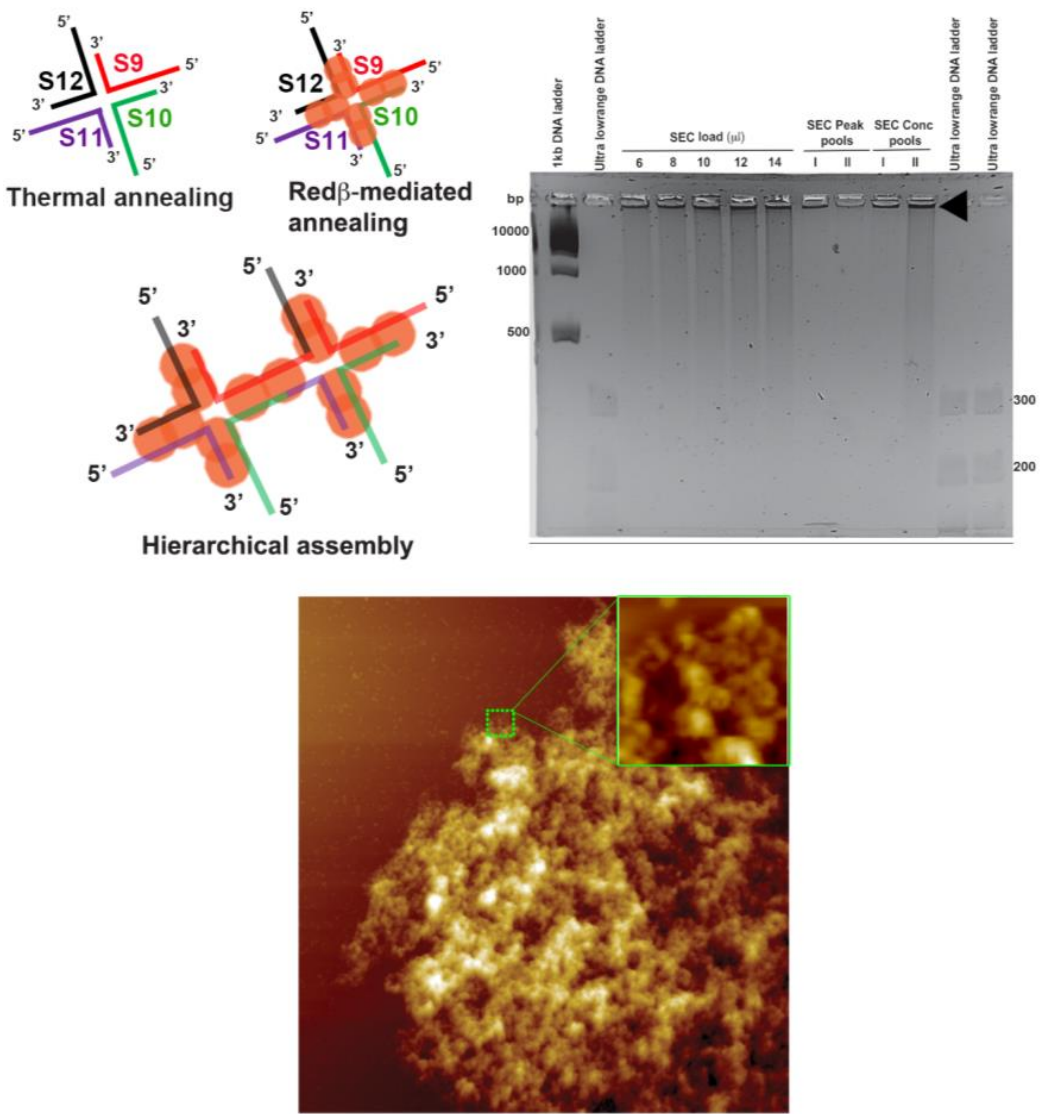

Figure 8. The schematic structures show the design and hierarchical assembly of a 66 mer HJ structure in which each arm has complementary sticky end sequences for hierarchical assembly. The sodium borate agarose gel analysis shows that the assembled structures are too large to enter the gel (indicated by the black arrowhead). The AFM image of the concentrated Peak I shows the efficient Red $\beta$-assisted hierarchical assembly of the 66 mer HJ structures. A zoomed section in the AFM image depicts the microstructures present inside the hierarchical structure. The AFM image has a size of $5 \times 5 \mu \mathrm{m}^{2}$ and a height scale of $20 \mathrm{~nm}$. 


\section{Materials and Methods}

\subsection{Protein Expression, Affinity, and Preparative Gel Filtration Chromatography}

For in vitro studies, $\operatorname{Red} \beta$ was purified using one-step Strep-tag II/Strep-Tactin affinity chromatography which allows mild protein purification under physiological conditions as described previously $[29,34,46]$. Quality and quantities of the protein from the two steps above were monitored by analytical SDS-PAGE analysis. Purified Strep-tag II-tagged protein was $>95 \%$ pure at a concentration range of $0.5-10.0 \mathrm{mg} / \mathrm{mL}$ when quantified on a Nanodrop 1000 (Thermo Fisher Scientific GmbH, Bremen, Germany).

\subsection{Establishment of a Holliday Junction Assembly Protocol Using Red $\beta$}

Different immobile HJ structures with different lengths were designed using UNIQUEMER 3D software version 1.0 [41]. Oligonucleotides were purchased from Metabion international AG (Planegg/Steinkirchen, Germany) (HPLC-purified). To optimize HJ assembly, 10 pmol of each ssDNA was incubated with $10,20,40$, or $80 \mathrm{pmol}$ of $\operatorname{Red} \beta$ at $37^{\circ} \mathrm{C}$ for $20 \mathrm{~min}$ in four sterile $1.5 \mathrm{~mL}$ Eppendorf tubes. After this step, all reaction contents from respective ratios were mixed in one sterile $1.5 \mathrm{~mL}$ Eppendorf tube (final volume $20 \mu \mathrm{L}$ ) and incubated at $37^{\circ} \mathrm{C}$ for $20 \mathrm{~min}$. The reaction was stopped by adding $4 \mu \mathrm{L}$ of 6 using $1 \times$ sodium borate buffer DNA loading dye and $3 \mu \mathrm{L}$ of $50 \%$ glycerol. As controls, each individual ssDNA was also loaded. The reaction mixtures were loaded and electrophoresed on $2 \%$ or $3 \%$ sodium borate agarose gels using $1 \times$ sodium borate buffer. After electrophoresis, gels were stained with $1 \times$ sybrGold (Thermo Fisher Scientific GmbH, Bremen, Germany) in 1× sodium borate buffer for $15 \mathrm{~min}$ at $25{ }^{\circ} \mathrm{C}$. Visualization of DNA was carried out using the Gel DocTM XR+ imaging system (Bio-Rad laboratories $\mathrm{GmbH}$, Feldkirchen, Germany). All the sequences are listed in Table S1.

For AFM imaging of 44 mer, 66 mer, and 88 mer HJ structures assembled at room temperature (see Figures 1-3), 1:4 ratios (in $\mu \mathrm{M}$ ) of individual ssDNA sequences and Red $\beta$ were mixed in separate Eppendorf tubes and incubated at $37^{\circ} \mathrm{C}$ for $20 \mathrm{~min}$. Then, the complete volume of all the ssDNA-protein complexes was added to a sterile Eppendorf tube, mixed well, and incubated at $37^{\circ} \mathrm{C}$ for 20 min to facilitate HJ structure formation. The same protocol was used for the hierarchical structure assembly without SEC purification and AFM analysis at 5 and $24 \mathrm{~h}$ time intervals (see Figure S3). The AFM imaging of the HJ structures and hierarchical assembly are described in Section 3.5.

\subsection{Red $\beta$-Mediated Annealing and Purification of Hierarchical HJ Assemblies with Sticky Ends (S1S4 and S5S8)}

For S1S4 + Red $\beta, 12.5 \mu \mathrm{L}$ of 66 mer ssDNA S1, S2 and 88 mer ssDNA S3, S4 $(1 \mu \mathrm{M})$ was pipetted into four individual sterile $1.5 \mathrm{~mL}$ Eppendorf tubes. For S5S8 + Red $\beta, 12.5 \mu \mathrm{L}$ of 88 mer ssDNA S5, S6 and 66 mer ssDNA S7, S8 $(1 \mu \mathrm{M})$ was pipetted into four individual sterile $1.5 \mathrm{~mL}$ Eppendorf tubes. An amount of $370 \mu \mathrm{L}$ of $87 \mu \mathrm{M}$ Red $\beta$ (pre-incubated at $37^{\circ} \mathrm{C}$ for $20 \mathrm{~min}$ ) was pipetted into each of these 8 tubes and the final volumes were adjusted to $1250 \mu \mathrm{L}$ by addition of $870 \mu \mathrm{L}$ of sterile B1 buffer (50 mM Tris- $\mathrm{HCl} \mathrm{pH} 8.0,150 \mathrm{mM} \mathrm{NaCl}$, and $1 \mathrm{mM} \mathrm{MgCl} 2$ ). The reaction contents were mixed well by gentle pipetting and incubated at $25^{\circ} \mathrm{C}$ for $20 \mathrm{~min}$. Afterwards, the contents of all four tubes, namely S1, S2, S3, and S4, were mixed in a $15 \mathrm{~mL}$ Falcon tube and incubated overnight at $25^{\circ} \mathrm{C}$. Similarly, the contents of the other four tubes, namely S5, S6, S7, and S8, were mixed in another $15 \mathrm{~mL}$ Falcon tube and incubated overnight at $25^{\circ} \mathrm{C}$. Following overnight incubation, the reaction mixture S1S4 + Red $\beta$ was loaded using a $5 \mathrm{~mL}$ sample loop onto the preparative superdex $200 \mathrm{column}$ (16/600) (GE Lifesciences, Chicago, IL, USA) connected to an Äkta purifier (GE Healthcare, Chicago, IL, USA). The column was pre-equilibrated with B2 buffer (100 mM Tris- $\mathrm{HCl}$ pH 8.0, $150 \mathrm{mM} \mathrm{NaCl}$, and $1 \mathrm{mM} \mathrm{MgCl} 2$ ). Preparative size exclusion chromatography (SEC) was carried out at $1 \mathrm{~mL} / \mathrm{min}$ flowrate. The eluting fractions were collected and based on the profile of the peaks, and only the summit fractions from the peaks were analyzed and pooled. A similar protocol was followed for the reaction mixture S5S8 + Red $\beta$ as well. The eluting fractions were collected and pooled as described above. For the purpose of quality control, we performed purification of S1S4 + Red $\beta$ species as well 
as S5S8+Red $\beta$ species separately as the first step. Once we confirmed the purification of the desired species, we went further and combined S1S4 $+\operatorname{Red} \beta$ with the S5S8 $+\operatorname{Red} \beta$ species. Peak I pools and Peak II pools of S1S4 + Red $\beta$ with S5S8 + Red $\beta$ runs were combined appropriately and purified further by another preparative SEC run. The resulting peak fractions were grouped as Peaks I and II. Purified complexes were analyzed by agarose gel electrophoresis in order to visualize DNA and on $8 \%$ native PAGE or 4-16\% gradient BlueNative PAGE gels followed by colloidal coomassie staining to visualize the protein. Afterwards, the desired species were used for AFM imaging.

\subsection{Red $\beta$-Mediated Assembly of Two-Dimensional Hierarchical HJ Networks (S9S12)}

For the two-dimensional hierarchical network assembly, 4 sticky-end ssDNAs (66 nucleotides long), namely S9, S10, S11, and S12, which could assemble in a left-right and up-down manner (see Figure 8) were used along with Red $\beta$. We set up an optimization protocol to check the Holliday junction network formation by $\operatorname{Red} \beta$ similar to the S1S4 $+\operatorname{Red} \beta$ and S5S8 $+\operatorname{Red} \beta$ work above. SEC purification (see Figure 5) was used for enriching the S9S12 + Red $\beta$ species. Following SEC, peak fractions were pooled and analyzed on $2 \%$ sodium borate agarose gel to visualize the S9S12 DNA and S9S12 + Red $\beta$ species. We used $8 \%$ native PAGE gel followed by colloidal coomassie staining to visualize the protein present in the S9S12 + Red $\beta$ complex. Afterwards, the desired species from Peak I was used for AFM imaging.

\subsection{AFM Imaging}

An amount of $5 \mu \mathrm{L}$ of the Red $\beta$-annealed HJ assemblies was deposited onto freshly cleaved mica surfaces. An amount of $100 \mu \mathrm{L}$ of fresh B2 buffer was added and the samples were allowed to adsorb for $15 \mathrm{~min}$. The samples were washed with $5 \mathrm{~mL}$ of HPLC-grade water and dried with a stream of ultrapure air. The AFM images were recorded in intermittent contact mode using an Agilent 5100 AFM (Agilent Technologies, Inc., Santa Clara, California, CA, USA) and HQ:NSC18/Al BS cantilevers (MikroMasch Europe, Wetzlar, Germany).

\section{Conclusions}

In this study, we have successfully optimized the conditions for the assembly of blunt- or sticky-ended HJ structures using $\operatorname{Red} \beta$. We have shown that these assembled structures are stable and hence could be purified by SEC. Our experiments with increasing lengths of $\mathrm{HJ}$ arms using three different lengths of ssDNA substrates support previous findings concerning the monomer spacing on DNA [29]. Most importantly, however, we have successfully demonstrated the ability of Red $\beta$ to assist in the concerted annealing of $\mathrm{HJ}$ structures and their hierarchical assembly into complex networks. As we have employed the full-length Red $\beta$ in this study, we observed left-handed helical filaments with curved ends. Future studies employing purified DNA binding domains or shorter DNA binding peptides of Red $\beta$ could aim at having more rigid-ended complex HJ assemblies. This could open up new avenues in the fields of macromolecular patterning and DNA nanotechnology.

Supplementary Materials: The following are available online, Red $\beta$-mediated annealing and purification of 88 mer HJ structures, gel analysis of the purified and enriched 88 mer HJ structures and corresponding AFM images, AFM images of hierarchical structures with SEC purification, AFM images of individual HJ structures and hierarchical structures without purification, oligonucleotide sequences.

Author Contributions: Conceptualization, S.R., S.S. and A.K.; methodology, S.R., S.S. and A.K.; validation, S.R., S.S. and A.K.; formal analysis, S.R. and S.S.; investigation, S.R., S.S. and C.K.; resources, A.F.S., G.G. and A.K.; data curation, S.R., S.S. and C.K.; writing-original draft preparation, S.R. and S.S.; writing-review and editing, S.R., S.S., C.K., G.G., A.F.S. and A.K.; visualization, S.R. and S.S.; supervision, G.G., A.F.S. and A.K.; project administration, A.K.; funding acquisition, A.F.S. All authors have read and agreed to the published version of the manuscript.

Funding: This work was supported by funding from the Deutsche Forschungsgemeinschaft grant STE 903/6-1 "Initiation of homologous re-combination by Red beta and other single strand annealing proteins" to A.F.S. S.S. 
was supported by the Deutsche Forschungsgemeinschaft (DFG, German Research Foundation) STE903/6-1 and by Germany's Excellence Strategy-EXC-2068-390729961-Cluster of Excellence Physics of Life of TU Dresden.

Conflicts of Interest: The authors declare no conflict of interest.

\section{References}

1. Brázda, V.; Laister, R.C.; Jagelská, E.B.; Arrowsmith, C. Cruciform structures are a common DNA feature important for regulating biological processes. BMC Mol. Biol. 2011, 12, 33. [CrossRef]

2. Eichman, B.F.; Ortiz-Lombardía, M.; Aymamí, J.; Coll, M.; Ho, P.S. The Inherent Properties of DNA Four-way Junctions: Comparing the Crystal Structures of Holliday Junctions. J. Mol. Biol. 2002, 320, 1037-1051. [CrossRef]

3. Yan, J.; Hong, S.; Guan, Z.; He, W.; Zhang, D.; Yin, P. Structural insights into sequence-dependent Holliday junction resolution by the chloroplast resolvase MOC1. Nat. Commun. 2020, 11, 1417. [CrossRef]

4. Mount, A.R.; Mountford, C.P.; Evans, S.A.G.; Su, T.-J.; Buck, A.H.; Dickinson, P.; Campbell, C.J.; Keane, L.M.; Terry, J.G.; Beattie, J.S.; et al. The stability and characteristics of a DNA Holliday junction switch. Biophys. Chem. 2006, 124, 214-221. [CrossRef]

5. Panyutin, I.G.; Biswas, I.; Hsieh, P. A pivotal role for the structure of the Holliday junction in DNA branch migration. EMBO J. 1995, 14, 1819-1826. [CrossRef] [PubMed]

6. Panyutin, I.G.; Hsieh, P. The kinetics of spontaneous DNA branch migration. Proc. Natl. Acad. Sci. USA 1994, 91, 2021-2025. [CrossRef]

7. Komori, K.; Sakae, S.; Shinagawa, H.; Morikawa, K.; Ishino, Y. A Holliday junction resolvase from Pyrococcus furiosus: Functional similarity to Escherichia coli RuvC provides evidence for conserved mechanism of homologous recombination in Bacteria, Eukarya, and Archaea. Proc. Natl. Acad. Sci. USA 1999, 96, 8873-8878. [CrossRef]

8. Seeman, N.C. Biochemistry and structural DNA nanotechnology: An evolving symbiotic relationship. Biochemistry 2003, 42, 7259-7269. [CrossRef]

9. Seeman, N.C. Nucleic acid junctions and lattices. J. Theor. Biol. 1982, 99, 237-247. [CrossRef]

10. Lu, M.; Guo, Q.; Mueller, J.E.; Kemper, B.; Studier, F.W.; Seeman, N.C.; Kallenbach, N.R. Characterization of a bimobile DNA junction. J. Biol. Chem. 1990, 265, 16778-16785.

11. Marky, L.A.; Kallenbach, N.R.; McDonough, K.A.; Seeman, N.C.; Breslauer, K.J. The melting behavior of a DNA junction structure: A calorimetric and spectroscopic study. Biopolymers 1987, 26, 1621-1634. [CrossRef]

12. Chen, J.H.; Churchill, M.E.; Tullius, T.D.; Kallenbach, N.R.; Seeman, N.C. Construction and analysis of monomobile DNA junctions. Biochemistry 1988, 27, 6032-6038. [CrossRef]

13. Seeman, N.C.; Kallenbach, N.R. Design of immobile nucleic acid junctions. Biophys. J. 1983, 44, 201-209. [CrossRef]

14. Wemmer, D.E.; Wand, A.J.; Seeman, N.C.; Kallenbach, N.R. NMR analysis of DNA junctions: Imino proton NMR studies of individual arms and intact junction. Biochemistry 1985, 24, 5745-5749. [CrossRef] [PubMed]

15. Wu, D.Q.; Kan, M.K.; Sato, G.H.; Okamoto, T.; Sato, J.D. Characterization and molecular cloning of a putative binding protein for heparin-binding growth factors. J. Biol. Chem. 1991, 266, 16778-16785. [PubMed]

16. Mikheikin, A.L.; Lushnikov, A.Y.; Lyubchenko, Y.L. Effect of DNA supercoiling on the geometry of holliday junctions. Biochemistry 2006, 45, 12998-13006. [CrossRef]

17. Vander Zanden, C.M.; Rowe, R.K.; Broad, A.J.; Robertson, A.B.; Ho, P.S. Effect of Hydroxymethylcytosine on the Structure and Stability of Holliday Junctions. Biochemistry 2016, 55, 5781-5789. [CrossRef]

18. Ho, P.S. Structure of the Holliday junction: Applications beyond recombination. Biochem. Soc. Trans. 2017, 45, 1149-1158. [CrossRef]

19. Zheng, J.; Birktoft, J.J.; Chen, Y.; Wang, T.; Sha, R.; Constantinou, P.E.; Ginell, S.L.; Mao, C.; Seeman, N.C. From molecular to macroscopic via the rational design of a self-assembled 3D DNA crystal. Nature 2009, 461, 74-77. [CrossRef]

20. Bergen, A.; Rudiuk, S.; Morel, M.; Le Saux, T.; Ihmels, H.; Baigl, D. Photodependent Melting of Unmodified DNA Using a Photosensitive Intercalator: A New and Generic Tool for Photoreversible Assembly of DNA Nanostructures at Constant Temperature. Nano Lett. 2016, 16, 773-780. [CrossRef]

21. Fu, Y.; Zeng, D.; Chao, J.; Jin, Y.; Zhang, Z.; Liu, H.; Di, L.; Ma, H.; Huang, Q.; Gothelf, K.V.; et al. Single-step rapid assembly of DNA origami nanostructures for addressable nanoscale bioreactors. J. Am. Chem. Soc. 2013, 135, 696-702. [CrossRef] [PubMed] 
22. Jungmann, R.; Liedl, T.; Sobey, T.L.; Shih, W.; Simmel, F.C. Isothermal assembly of DNA origami structures using denaturing agents. J. Am. Chem. Soc. 2008, 130, 10062-10063. [CrossRef]

23. Kopielski, A.; Schneider, A.; Csáki, A.; Fritzsche, W. Isothermal DNA origami folding: Avoiding denaturing conditions for one-pot, hybrid-component annealing. Nanoscale 2015, 7, 2102-2106. [CrossRef] [PubMed]

24. Myhrvold, C.; Dai, M.; Silver, P.A.; Yin, P. Isothermal self-assembly of complex DNA structures under diverse and biocompatible conditions. Nano Lett. 2013, 13, 4242-4248. [CrossRef] [PubMed]

25. Sobczak, J.-P.J.; Martin, T.G.; Gerling, T.; Dietz, H. Rapid folding of DNA into nanoscale shapes at constant temperature. Science 2012, 338, 1458-1461. [CrossRef]

26. Wang, D.; Liu, Q.; Wu, D.; He, B.; Li, J.; Mao, C.; Wang, G.; Qian, H. Isothermal Self-Assembly of Spermidine-DNA Nanostructure Complex as a Functional Platform for Cancer Therapy. ACS Appl. Mater. Interfaces 2018, 10, 15504-15516. [CrossRef]

27. Caldwell, B.J.; Bell, C.E. Structure and mechanism of the Red recombination system of bacteriophage $\lambda$. Prog. Biophys. Mol. Biol. 2019, 147, 33-46. [CrossRef]

28. Kuzminov, A. Homologous Recombination-Experimental Systems, Analysis, and Significance. EcoSal Plus 2011, 4. [CrossRef]

29. Erler, A.; Wegmann, S.; Elie-Caille, C.; Bradshaw, C.R.; Maresca, M.; Seidel, R.; Habermann, B.; Muller, D.J.; Stewart, A.F. Conformational adaptability of Redbeta during DNA annealing and implications for its structural relationship with Rad52. J. Mol. Biol. 2009, 391, 586-598. [CrossRef]

30. Muyrers, J.P.P.; Zhang, Y.; Stewart, A.F. Techniques: Recombinogenic engineering-new options for cloning and manipulating DNA. Trends Biochem. Sci. 2001, 26, 325-331. [CrossRef]

31. Copeland, N.G.; Jenkins, N.A.; Court, D.L. Recombineering: A powerful new tool for mouse functional genomics. Nat. Rev. Genet. 2001, 2, 769-779. [CrossRef]

32. Zhang, Y.; Buchholz, F.; Muyrers, J.P.; Stewart, A.F. A new logic for DNA engineering using recombination in Escherichia coli. Nat. Genet. 1998, 20, 123-128. [CrossRef]

33. Ander, M.; Subramaniam, S.; Fahmy, K.; Stewart, A.F.; Schäffer, E. A Single-Strand Annealing Protein Clamps DNA to Detect and Secure Homology. PLoS Biol. 2015, 13, e1002213. [CrossRef] [PubMed]

34. Subramaniam, S.; Erler, A.; Fu, J.; Kranz, A.; Tang, J.; Gopalswamy, M.; Ramakrishnan, S.; Keller, A.; Grundmeier, G.; Müller, D.; et al. DNA annealing by Red $\beta$ is insufficient for homologous recombination and the additional requirements involve intra- and inter-molecular interactions. Sci. Rep. 2016, 6, 34525. [CrossRef] [PubMed]

35. Teschome, B.; Facsko, S.; Schönherr, T.; Kerbusch, J.; Keller, A.; Erbe, A. Temperature-Dependent Charge Transport through Individually Contacted DNA Origami-Based Au Nanowires. Langmuir 2016, 32, 10159-10165. [CrossRef] [PubMed]

36. Aryal, B.R.; Ranasinghe, D.R.; Westover, T.R.; Calvopiña, D.G.; Davis, R.C.; Harb, J.N.; Woolley, A.T. DNA origami mediated electrically connected metal-Semiconductor junctions. Nano Res. 2020, 13, 1419-1426. [CrossRef]

37. Shen, B.; Linko, V.; Tapio, K.; Pikker, S.; Lemma, T.; Gopinath, A.; Gothelf, K.V.; Kostiainen, M.A.; Toppari, J.J. Plasmonic nanostructures through DNA-assisted lithography. Sci. Adv. 2018, 4, eaap8978. [CrossRef]

38. Urban, M.J.; Dutta, P.K.; Wang, P.; Duan, X.; Shen, X.; Ding, B.; Ke, Y.; Liu, N. Plasmonic Toroidal Metamolecules Assembled by DNA Origami. J. Am. Chem. Soc. 2016, 138, 5495-5498. [CrossRef]

39. Ramakrishnan, S.; Subramaniam, S.; Stewart, A.F.; Grundmeier, G.; Keller, A. Regular Nanoscale Protein Patterns via Directed Adsorption through Self-Assembled DNA Origami Masks. ACS Appl. Mater. Interfaces 2016, 8, 31239-31247. [CrossRef]

40. Liu, L.; Zheng, M.; Li, Z.; Li, Q.; Mao, C. Patterning Nanoparticles with DNA Molds. ACS Appl. Mater. Interfaces 2019, 11, 13853-13858. [CrossRef]

41. Zhu, J.; Wei, B.; Yuan, Y.; Mi, Y. UNIQUIMER 3D, a software system for structural DNA nanotechnology design, analysis and evaluation. Nucleic Acids. Res. 2009, 37, 2164-2175. [CrossRef]

42. Praetorius, F; Dietz, H. Self-assembly of genetically encoded DNA-protein hybrid nanoscale shapes. Science 2017, 355. [CrossRef]

43. Schiffels, D.; Szalai, V.A.; Liddle, J.A. Molecular Precision at Micrometer Length Scales: Hierarchical Assembly of DNA-Protein Nanostructures. ACS Nano 2017, 11, 6623-6629. [CrossRef]

44. Lilley, D.M. Structures of helical junctions in nucleic acids. Q. Rev. Biophys. 2000, 33, 109-159. [CrossRef] 
45. McKinney, S.A.; Freeman, A.D.J.; Lilley, D.M.J.; Ha, T. Observing spontaneous branch migration of Holliday junctions one step at a time. Proc. Natl. Acad. Sci. USA 2005, 102, 5715-5720. [CrossRef] [PubMed]

46. Skerra, A. Use of the tetracycline promoter for the tightly regulated production of a murine antibody fragment in Escherichia coli. Gene 1994, 151, 131-135. [CrossRef]

Sample Availability: Samples of the compounds are not available from the authors.

Publisher's Note: MDPI stays neutral with regard to jurisdictional claims in published maps and institutional affiliations.

(C) 2020 by the authors. Licensee MDPI, Basel, Switzerland. This article is an open access article distributed under the terms and conditions of the Creative Commons Attribution (CC BY) license (http://creativecommons.org/licenses/by/4.0/). 